\title{
Foreign Language Students' Perceptions of Their Identity
}

Learning another language is like becoming another person. Haruki Murakami

\begin{abstract}
Foreign language learning involves cognitive, affective, and social functioning of the persons involved in this experience. As a social practice, it is also related to the learners' perceptions of their identity, specifically to their language identity which refers to the relationship between one's sense of self and the language used to communicate. This implies that using a system of communication, the speaker develops a new sense of self that remains in a dynamic relation with other senses of self, based on (an)other language(s) the person knows.

Language learners' identity is no longer defined as fixed and stable but as "complex, contradictory and multifaceted" (Norton, 1997, p. 419). It is dynamic because learners enter into various discourses and negotiate their position within different communities of practice. Language both shapes and is shaped by identity of its users.

This article discusses how students of English as a foreign language perceive the role of this language in their construction of selves/identity. First, postmodern conceptualisations of identity and identity categories are presented along with their relevance to the field of Second Language Acquisition. Second, selected empirical studies pertaining to adult immigrant contexts, foreign language contexts, and study abroad contexts are briefly reported. Then the results of an empirical study on the students' of English $(n=83)$ perceptions of their identity in the context of foreign language learning are introduced. The study revealed that most of the participants realise complex relations between language learning and their identity and are aware of the effects that studying English (as well as other foreign languages) has on them. English gave them new possibilities in life, allowed them to communicate with people worldwide and make friends with them. They have new and interesting prospects for the future. It affected their personality by making them more open-minded and tolerant of otherness. The knowledge of English gives the students power, prestige, and opportunities to live and work in a changing world of complex social relations.
\end{abstract}

Keywords: foreign language learning, postmodern identity, investment, study abroad 


\section{Introduction}

Interest in identity in the context of second language learning and teaching has been gathering momentum since Firth and Wagner (1997) observed that second language acquisition (SLA) research should focus not only on cognitive language processes but it should also view language in a social and contextual perspective, thus broadening the traditional approach to SLA. They were sceptical about perceiving language users as native or non-native speakers, and made a point that native and non-native speakers have many identities, which is "a nonissue in SLA" (p. 292). Responding to their dissatisfaction with the dominant perspectives in SLA, Gass (1998) argued that the relevance of identity for language learning needs to be documented. Indeed, this has been done. First, research on identity puts the language learner in a broad social context. Second, power relations in this context have an impact on language learners' variable contact with target language communities. Third, there is a mutual relationship between the construction of individual identity, social practices, and resources which all may positively affect language learning. Fourth, what drives individuals to learn a language is not only motivation but also commitment to learning that has been termed investment. And finally, learners may imagine or desire communities to which they would like to belong so they have a more varied range of identities in the future (Kanno \& Norton, 2003; Norton, 2013, Norton \& Toohey, 2011).

Block (2007b) observes that the interest in identity and SLA resulted from the realisation that focusing on language and cognition was not sufficient to understand complex relations between second language learning and social ramifications in which it was anchored. This, in turn, has been connected with teaching language for communication, which requires interaction, and interaction itself requires participation in various social exchanges embedded in diverse sociocultural contexts. Moreover, growth in global mobility due to economic upheavals towards the 1980s made individuals change places and styles of living, which inevitably lead to questions concerning their identity. The development in information technology made multimodal communication possible, easy, and cheap, and, what is more, it also allows the individuals to assume virtual identities that may depart from their real life identities (Kramsch, 2013). Such sociopolitical and socioeconomic phenomena as globalization, consumerism, reconstruction of postcolonial and postcommunist national identities, or transnational migrations caused by wars, among others, imply complex relations between languages and identities (Pavlenko \& Blackledge, 2004).

Research on identity and SLA has bloomed since the 1990s and interesting relationships between identity and language learning processes have been identified (Norton \& Toohey, 2011). 
The paper focuses on the current understanding of identity that is founded on postmodernist thinking and has been accepted by many language and identity researchers. Then major research areas pertaining to identity issues are discussed. Finally, an empirical study on identity in the context of foreign language learning and use is presented and discussed.

\section{Identity in SLA Research}

Current approaches to language and identity in SLA are deeply rooted in poststructuralist theories of identity and associated with the work of Bakhtin, Bourdieu, Foucault, and Weedon. Christine Weedon (1997), for example, sees the value of language practices in positions associated with individual and group identity. Concerned with subjectivity, Weedon observes that language is the site where it is constructed. She understands subjectivity as "the conscious and unconscious thoughts and emotions of the individual, her sense of herself, and her ways of understanding her relations to the world" (1997, p. 28). The relations to the world are crucial because they shape individuals and are shaped by them (Norton \& Toohey, 2011). Individuals are allowed (or not allowed) to participate in discourse, in dialogic encounters with others in which they create their meanings in a specific social context although they may be limited by the fact of using language as a tool that had been used before (Bakhtin, 1981). Participation in activities involving language use conditions the emergence of dynamic language knowledge or competence (Hall et al., 2006).

Bourdieu (1977) argues that language symbolically represents the relationship between identity and power since language users are placed in a larger social network, and the perception of their utterances depends on their place in this network, in the social context as "speech always owes a major part of its value to the value of the person who utters it" (p. 652). The speakers' position in the social context may empower or marginalize them but since they need "not only to be understood, but to be believed, obeyed, respected, distinguished" (Norton, 2006, p. 503), they have to struggle for the right to speak. In addition, the language user's perception of the world and their activity in it are shaped by what they have lived through so far. Since they have experienced the world based on inequality and dominance, different power relations will be reflected in their interpersonal interactions with others (Menard-Warwick, 2005).

Relevant to the present discussion is Bourdieu's (1991) concept of cultural and symbolic capital. Cultural capital refers to "knowledge, skills and other cultural acquisitions, as exemplified by educational or technical qualifications," while symbolic capital refers to "prestige or honor" (1991, p. 14). These are 
complemented by linguistic capital that involves language varieties valued by a given society. These forms of capital are unequally distributed in a society and therefore tensions arise in the situation when one variety, for example the standard language which is the language of education, competes with the learnes' language used locally. Linguistic capital, that is the knowledge of the standard or official language, may be insufficient to let the language users (e.g., immigrants) access the cultural and symbolic capital and thus to build power relations in the community, to have the voice, the right to speak, to hear, and to be heard. Also Foucault's (1984) concern with social relations that are regulated mostly by language - the power itself-has been included into theories focused on language and identity (Menard-Warwick, 2005). Taking the tenets of postructuralism into consideration, identity in SLA context may be defined as "the way a person understands his or her relationship to the world, how that relationship is constructed across time and space, and how the person understands possibilities for the future" (Norton, 2013, p. 4). Norton emphasises that future is "central to the lives of many language learners, and is integral to an understanding of both identity and investment" (Norton, 2013, p. 4).

The idea of "investment" derives from Bourdieu's writing and refers to the learner's desire or the lack thereof, to engage in social practices of the target language community to get access to symbolic capital that will increase their cultural capital and social power. In other words, commitment to learning the target language is necessary if the learner is to engage in the practices of the largest language community and thus to develop their linguistic capital (Norton, 2013).

\section{Identity Categories}

Postmodern theories have placed identity within a broad sociocultural and sociohistoric context. While modern conceptions of identity defined it as fixed and homogeneous, from the postmodern perspective it is fragmented, contested, complex, multifaceted, and dynamic (Norton 1997; Block 2007a), "fluid, context-dependent and context-producing, in particular historical and cultural circumstances" (Norton \& Toohey, 2011, p. 419). Identity is complex because it operates in many dimensions of human life such as ethnicity, race, nationality, migrant status, gender, social class, and language.

Ethnic identity is characteristic of cultural groups with a common history, descent, beliefs, and practices, language, and religious beliefs. It is "a form of collective identity" (Puri, 2004, p. 174) based on cultural ties. Similarly, national identity is also based on shared history, descent, belief system, practices, 
language, and religion. However, these are associated with a nation state, and not with a cultural group. Racial identity, in turn, refers to biological or genetic make-up, that is, racial phenotype.

Migrant identity refers to the identity of people who left their home countries and moved to other countries where they settled. It includes classical immigrants who settled in the new country and never considered returning to their old country, but also expatriates who voluntarily decide to live abroad, however, they may return to their home country whenever they want. There are also transmigrants who share ethnic, religious, or national identities or geographical places of origin, and who have settled in a new country but decided to keep economic and cultural ties with their homeland, creating formal and informal networks that create "transnational social spaces" (Block, 2007a, p. 33). In contrast to classical immigrants, transmigrants' cultural and personal loyalties are not bound with the new country. Thus, migrant identity refers to whether migrants decide to live in a new country as classical migrants, expatriates, or transmigrants.

Gender identity is no longer conceived of as biologically determined and stable, but as socially constructed and dynamic (e.g., Bulter's idea of gender as performativity, 1999). Gender identity, then, is based on the "nature of conformity to socially constructed notions of feminities and masculinities, as well as orientations to sexuality and social activity" (Block, 2007a, p. 43).

The concept of social class identity has also been revised due to changing conditions of life. It was traditionally associated with "wealth, occupation, education and symbolic behaviour (e.g., language, clothing, pastimes)" (Block, 2007a, p. 37). It is now represented by economic, cultural, symbolic, and social capital, the concepts deriving from Bourdieu's theories. In addition, social classes were traditionally divided into upper, middle, and working class (the division based on occupation). However, changes in economy at the end of the twentieth century have altered working conditions both for manual workers and for university professors. According to Reich (1991), three new classes related to occupation can be identified, that is, in-person servers, routine producers, and symbolic analysts. The division is based on the type of work and the presence of consumers of this work. Thus, in-person servers, for example teachers, secretaries, bus drivers, or hairdressers, perform repetitive tasks in the presence of the consumers of their work. Routine producers, that is, blue- and whitecollar workers, are also involved in repetitive tasks, but they perform them in the absence of the consumers of their work. Symbolic analysts control the other two classes, they identify and solve problems. They are highly skilled and very well educated and they become more and more a part of an international "socioeconomic and intellectual elite" (Block, 2007a, p. 39).

Eventually, there is language identity. It is defined as "the assumed and/or attributed relationship between one's sense of self and a means of communica- 
tion which might be known as language (e.g., English) a dialect (Geordie) or a sociolect (e.g., football-speak)" (Block, 2007a, p. 40). This relationship may take three forms, that is, language expertise, language affiliation, and language inheritance (Rampton, 1990, in Block, 2007a). Expertise concerns proficiency in the use of a means of communication that allows the speaker to be accepted by other speakers of this variety of language. Affiliation is related to attitudes and feelings about a given form of communication whereas inheritance is about being born into a family or a community that uses a given form of communication.

In addition, language identity may also be interpreted as "acts of identity," which means that all utterances simultaneously point to the speaker's identity and to its ethnic, national, gender, and social class dimensions. In other words, producing an utterance, the speakers disclose other aspects of their identity.

Language identity is about relationship to language and speech communities as well. Language communities adhere to standard and normative forms whereas speech communities are characterized by the actual use of language. It involves communication that is not limited to linguistic means such as accent, pronunciation, morphological, syntactic, and lexical choices. Verbal communication is supported by other multisensory non-verbal elements, for example by hairstyle, clothes that one is wearing, or facial expressions (Block 2007a).

Identity is also related to audibility, both in the first and in the second language. It derives from the right accent and social and cultural capital that allow the speaker to be accepted as a member of a community of practice. This aspect of language identity is particularly relevant to second language acquisition contexts that characterize immigrant populations around the world (Piasecka, 2012).

The above considerations do imply that identity is complex and operates on many levels that interact dynamically. As far as language identity is concerned, it indicates other dimensions of identity. When people use or learn to use more than one language, other identities are performed. Although some aspects of their identity remain stable, for example: race, gender (though this may be contested) or social class, others, for example, language or migrant identities change as a result of using another language. To reiterate, language identity is about the relationship between one's sense of self and the language used to communicate. This implies that using a system of communication, the speaker develops a new sense of self that remains in a dynamic relation with other senses of self, based on (an)other language(s) the person knows. And this is one of the reasons for using the quotation opening this article. 


\section{Second Language Identities}

Second language identities can be analysed in three contexts, that is, adult immigrant contexts, foreign language contexts, and study abroad contexts (Block, 2007a). Selected empirical studies pertaining to these three contexts are briefly reported in the following sections.

\section{Adult Immigrant Contexts}

As far as adult immigrant language learners are concerned, large scale studies were conducted in Europe, the U.S., and Canada. European Science Foundation carried out a longitudinal study that aimed to analyse fossilized interlanguages along with processes and factors involved in second language acquisition. The study was carried out in five countries over the period of five years, and included five target languages, six mother tongues and ten interlanguages (Perdue, 1984, in Norton, 2013). The researchers also wanted to find out how immigrants interact with target language speakers in a broader sociopolitical context. This issue is particularly relevant to the present discussion as interaction is indispensable for the development of communicative competence. Successful communication between native and non-native speakers of the language depends on the negotiation of meaning which brings about mutual understanding and supports language learning. The findings show that adult immigrants are often discriminated and therefore they have a limited access to social interaction. When they interact, they struggle to understand native speakers though native speakers are not concerned whether the learners understand. Immigrants learn to communicate in difficult sociocultural contexts, with limited L2 proficiency and assymetrical power relations (Bremer et al, 1993, 1996, in Norton, 2013).

Hispanic immigrant women from Rockhill's study (1987a, 1987b) on literacy were very ashamed about not knowing English and not being able to communicate in this language efficiently. They blamed themselves for not making enough progress although they lived in difficult social and material conditions and they were primarily concerned about making the lives of their children and husbands successful. Their needs such as education and literacy in English were of secondary importance. Norton (2013) argues that their learning, exposure to, and opportunities to practice English were shaped mostly by their identities as women.

Norton (2013) carried out a case study of five immigrant women in Canada to "develop an enhanced understanding of the relationship between identity and language learning" (p. 86). The women were good language learners as 
evidenced by the fact that they participated in a diary study. Yet, they felt marginalized because they were immigrants and this marginalization was a cause of problems and difficulties when they were communicating with target language speakers. One of women wrote "I feel comfortable using English with people I know and have confidence with" (Norton, 2013, p. 95). Moreover, these women had problems with finding jobs matching their qualifications, which made their access to the cultural, symbolic, and linguistic resources of the target community more difficult.

The selected studies briefly discussed above show that adult immigrants invest and are motivated to learn the target language but their learning is shaped and shapes complex social, professional, and cultural relations. Living in a new country entails challenges to their identity constructed by their native languages. Often, the new socio-economic context changes class membership so in the new country the immigrants enter a social class that is lower when compared to their native country social class. In addition, some immigrants working in a new social context have to cope with the duties imposed by the fact that they are responsible for maintaining home and family life, which-along with a low level of education - limits their participation in L2 courses (Goldstein, 1996) and thus has an impact on their emerging new subject positions.

\section{Study Abroad Contexts}

American colleges and universities offer students of foreign languages an opportunity to study abroad for a semester or a year. Although study abroad is challenging in terms of language knowledge and cultural differences, it allows the students to practise their language skills in real life conditions and thus to develop their communicative competence. However, many other issues emerge with respect to this form of study. Kinginger (2009) points to the learner's identities, desires, and motives along with a wide range of encounters which involve communication and thus provide opportunities for language learning. Two studies reported below show how these encounters may differ.

Analysing the diaries of American students studying Russian in Russia, and the scores they received on Oral Proficiency Interview, Polanyi (1995) found gender differences in listening and speaking skills scores. Young males improved more than young females after the study abroad period. The researcher explains this difference by the behaviours of Russian males who expect some kind of sexual favours from their foreign female interlocutors, which discourages the latter from interacting with them and makes them feel uneasy about the sexual overtones in the interactions.

The purpose of Kinginger's (2004) study was to present the history of a foreign language learner and to show how foreign language learning experience 
reconstructs identity. She describes Alice, an American learner of French, who went to France to study the language and culture to become more refined. For her, France was romantic, full of monuments of the past, inhabited by refined and elegant people. The France she encountered was far from her idealised picture and she had to revise her image of the country. She also invested a lot of time and energy to establish informal interpersonal relations with French students and, due to her persistence, not only did she develop her knowledge of French, but she became more goal-oriented, she built social relations, and became more interested in "sophisticated topics" (e.g., politics) and, having completed college education, she changed her social class.

In Europe, the international student exchange program called Erasmus+ allows many young people to study abroad to improve language skills, to gain self-confidence and independence, and to discover and learn about a new culture (http://ec.europa.eu/programmes/erasmus-plus/opportunities/students en). The Erasmus impact study (2014) demonstrates that studying abroad has positive effects on employment opportunities of the program participants due to, among others, soft skills developed during their time abroad. It also refers to Europeanisation and internationalisation of students' identity. Sigalas (2010) wanted to find out whether study abroad within the Erasmus program and interpersonal contacts established during the stay promote a European identity. It appeared that although program participants socialized with other Europeans, their contacts with host country students were limited and their European identity was not strengthened. On the other hand, increased socializing with Europeans had a positive average influence on European identity.

American students feel uneasy about heterosexual relations abroad, but this is not a problem for Erasmus students abroad. They are more experienced travellers who are more aware of what they may expect when studying. They do not exhibit an enhanced national identity, which was observed in American students abroad. Block (2007a) explains that the difference may stem from the fact that European students have more experience traveling and staying abroad, whereas Americans are "relatively unseasoned and even naïve travelers on their first - and quite likely last-ever-extensive sojourn outside the US" (p. 180).

\section{Foreign Language Learning Contexts}

Studies concerning identity and foreign language learning are less numerous than the ones addressing adult immigrant and study abroad contexts and they focus rather on subject positions related to formal educational settings (Block, 2007b). Lantolf and Genung's (2003) study, for example, reports the foreign 
language learning experience of a person (actually, it was Genung, PG) who enrolled in the course of Mandarin and was not satisfied with the manner in which the langauge was taught, nor with the way the teachers reprimanded the students for not being properly prepared for class, thus humiliating them and creating a hostile classroom atmosphere. What mattered in the course were good grades but not learning how to use the language, so PG, though frustrated, worked to achieve this goal, which was in contrast to her understanding of what is involved in language learning.

McMahill (1997) reports how Japanese women participating in "grassroots feminist English classes" (p. 612) worked on their subject positions. The course was focused both on language development and discussions of such problems as discrimination on the job market, women rights, ethnic identity, and personal histories of the participants. By talking about these problems through the medium of English, the women moved from the position of language learners to the position of those who are concerned about the important issues in their lives.

Piasecka (2012) designed a study to find out whether Polish students of English at the tertiary level realise the possible influence of this language on their sense of self and on their construction of identity. The study involved 39 participants, eight from a foreign languages teacher training college, 19 undergraduate second year university students of English and 12 graduate university students of English. They wrote how learning and studying English at tertiary education institutions influenced who they are. The results show that studying English affects the participants' identity by enhancing their self-confidence, broadening their minds and providing them with greater job opportunities. Cross-cultural communication allows them to know other people, to develop knowledge of languages and of other cultures, which results in a greater openness to otherness and supports tolerance. They realise they can stay and work abroad, finding an alternative to what they can do in their home country. Because of the knowledge of a foreign language, they also have access to various sources of information, which makes them more informed and critical about various opinions and viewpoints. Their language identity appeared dynamic and multifaceted. The knowledge of English gives the students power, prestige, and opportunities to live and work in the globalized world.

A similar study, which may be regarded as an extension of the 2012 study, was carried out in 2018 with a purpose to investigate identity issues in the context of studying English. It is reported in the following section. 


\section{How Foreign Language Students Perceive Their Identity-The Study}

The aim of the study was to find out how students of English perceive the role of this language in their construction of selves/identity. Since increasing numbers of international students decide to study at Polish universities, there was an opportunity to include them in the study and collect their opinions and ideas about the impact of foreign language learning on their sense of self. Therefore, the research questions formulated for the purpose of the study are:

Research Question 1: Does learning English (and other foreign languages) influence the learners' identity?

Research Question 2: If it does, what is this influence?

Altogether, 83 students participated in the study. There were 60 undergraduate (BA) university students of English Philology (46 females, including three Ukraininan students, and 14 males). The youngest student in this group was 17, the oldest - 21. They knew from two to six languages. Eight graduate university students of English Philology (seven females, one male) were between 22 and 25 years old (mean 23.25 years) and they knew from two to four foreign languages. Ten Erasmus students, undergraduate and graduate level, English Philology (seven females, three males) came from Turkey, Greece, and Spain, they were between 19 and 22 years old and they knew two or three languages. Five doctoral students were enrolled in the English Philology Applied Linguistics program (four females, one male), and their age varied (from 24 to over 40). Thus, second language identities involved two contexts, that is, study abroad contexts (Erasmus + students and Ukrainian students) and foreign language contexts (Polish students of English Philology; cf. Block, 2007a). It has to be taken in account, however, that for all the participants English was a foreign language.

The participants were asked to answer the following questions in writing: How has the knowledge of English (and other foreign languages) influenced the sense of who you are? Your identity? Your style of living? Your activities in the present? Your prospects for the future? They wrote the answers to the question during classes held by the researcher. Polish students could write in the language they felt most confident with (Polish or English) but foreign students did not have the choice - they had to write in English because the researcher did not know their native languages. They were advised to use between 150-200 words. When the texts were collected, it appeared that all were written in English.

The texts were then analysed to identify the effects of L2 learning on the students' selves. The researcher read all the papers, paying attention to lexical phrases used to decribe the influences (or the lack thereof), made a list of the 
influences described by the participants and counted the frequency of individual occurrences. This allowed the researcher to create thematic categories. For example, when the answers were "Thanks to English I'm learning about other cultures" (1), or "Knowledge of English affects us in a good way, we understand other people better, and also their culture" (2), or "I'm open-minded to other cultures" (3), they were assigned to the category "Developing knowledge and understanding of other cultures," except example (2) which also shows the positive impact of the knowledge of a foreign language on one's identity. Eventually, the participants' opinions were grouped into nine categories and rank ordered. In addition, the results were analysed according to the level of studies and by the students' country of origin (Erasmus + students). Also, the most representative opinions related to the participants' perceptions of self were selected and they are presented in the results section.

\section{Results}

Fourteen participants (16.9 per cent) declared that learning English had no effect on their sense of self although they noted positive effects of learning English on many aspects of their life. Sixty-nine participants wrote that learning English gave them new possibilities in life, allowed them to communicate with people worldwide and make friends with them. It also gave them new and interesting prospects for the future.

The effects of learning English on the participants' perceptions of their identity (categories) are listed below. The numbers in the parentheses show the frequency of the views for each category, found in the data:

- Ability to communicate with speakers of other languages, both at home and abroad (40).

- Greater job opportunities and finding a way of life (becoming a teacher/ interpreter/ translator or any other profession involving the proficient use of English; possibility to live and work abroad) (35).

- Entertainment - watching films, listening to songs, playing online gamesalso an opportunity to learn and understand the language (21).

- Enhanced self-confidence, especially underscored by females (21).

- Travel (15).

- Making friends with foreigners because of the ability to communicate in English (12).

- Developing knowledge and understanding of other cultures (11).

- Choice of studies (9).

- Openness to otherness (5).

In the majority of cases the participants showed awareness about the effects that studying English (as well as other foreign languages) has on them. Excerpts 
from some texts are given in what follows. The texts appear as they were written by the participants. The first section presents texts that highlight connections between language and identity (A), whereas the second section focuses on texts that do not find any connection between language and identity (B). All the opinions have been presented in the original.

A. English has influenced my identity.

The knowledge of English influenced me a lot. Thanks to English I've become more confident and open to people ... I don't have language barriers any more. ... It shapes me.... I feel clever and intelligent (a 20-years-old undergraduate female student).

It helped me understand the complexity of the world, that I am a part of the global society. Also, that people living far away are not so distant if you know their language. ... I don't want to stop developing my language abilities, I've started learning Spanish but in the future I want to learn French and Japanese. ... So the knowledge of foreign languages has had a great impact on my life and my identity (a 19-years-old undergraduate male student).

In my opinion, every experience affects us in a good way and the knowledge of English too. It is said that every language means one human being so how many languages we learn we can develop our characteristics. ... We can understand other people better, ... their culture. ... We can be more developed and open-minded (a 22-years-old Erasmus + female student from Turkey).

The knowledge of English opened me a lot of doors to work and learn (a 21-years-old Erasmus + female student from Spain).

I believe the knowledge of English influenced me to a great extent in many areas of my life. ... English shaped my identity as I believe that by learning a language you become more open to other cultures and beliefs (a 19-yearsold Erasmus + male student from Greece).

The knowledge of English allowed me to interact with people from different countries and with different backgrounds. This connection made me understand and experience things I wouldn't be able to do if I didn't know the language. For example, the integration with other students during my Erasmus + experience (a 24-years-old graduate female student).

Learning English has influenced my identity immensly. My life has been revolving around the English language since my adolescence. ... I must admit that without learning English I would not do what I am doing now 
and I would not be the person that I am now. When abroad I do not feel ashamed or confused as I know I have no problems in communication with the locals. ... The fact that I have two Englishmen in my closest family also forced me to improve my English (a PhD female student).

B. No connection between English and identity.

I think that knowledge of English didn't influence me that much. Maybe only in that I can watch films in English, I can communicate with people who know English and that it helped me in chosing the thing I want to study (a 19-years-old undergraduate female student).

There wasn't much influence in the sense of my life just because I know English. I didn't change my style of living or activities. It may influence my prospects for the future because I hope and I want to make money from it (a 19-years-old undergraduate male student).

Having the knowledge of English affects my life in positive way. Actually I am happy while I am speaking because speaking English was my dream and I am living this dream. ... To be honest, it doesn't change my identity because my daily life is nearly same. When I saw people who need help, I was helping (a 22-years-old Erasmus+ male student from Turkey).

The knowledge of English and other languages does not influence the sense of who I am. However, it allows me to read English texts so I don't have to look for translations (a 23-years-old graduate male student).

\section{Discussion}

The students' perceptions of their identity vis á vis foreign language learning and use can be discussed from the social point of view, from the point of view of cultural knowledge as well as from the point of view of personal growth. Most of the participants are aware of the mutual relationship between language and identity and of the crucial role of language with respect to the positions they can assume in various spheres of life (Research Question 1). These relations vary and affect many aspects of the participants' life and functioning (Research Question 2). The participants value social bonds, which is why they underscore the importance of communication with foreigners both at home and abroad. They also want to make friends with foreigners. The ability to communicate in a foreign language empowers them-they can have an interesting job at home but they can also work abroad. By communicating, they develop interpersonal relations with speakers of other languages, thus increasing their cultural capital which allows them to understand their relationship to the world. 
They decided to study English at the university because they know English. Therefore they write that their future is also related to English - they realize their employment opportunities both at home and abroad increase due to the fact that they know this language. In the light of the postmodern theories of identity it may be observed that they develop their subjectivity understood as participation in a variety of activities that allow them to interact with other users of the language (Norton, 2013). This participation is possible since they have accumulated linguistic capital that gives them access to symbolic and cultural capital. The knowledge of English allows access to different ways of entertainment which is also a way to knowledge because both language use and language growth are involved.

The participants also refer to experiencing culture(s) connected with foreign languages they learn. This has an impact not only on their knowledge but also on their personality. They declare that by learning a foreign language and experiencing its culture/s, they become more open and tolerant to otherness and difference, they feel clever and intelligent. They are not ashamed or confused about not being able to communicate with foreigners. Communicating in a foreign language builds their self-confidence. In consequence, they can cope with new and challenging situations. Interestingly, the enhanced understanding and contact with (an)other language(s) and its/their cultures is more frequently voiced by Erasmus and Ukrainian students than by Poles. The metaphor of doors used by one of the foreign students implies that learning a foreign language opens new possibilities and gives learners access to knowledge and other nonmaterial resources.

The case of students who declare that learning and using English has had no impact on their sense of self is quite intriguing. As the excerpts from their texts show, they realise that the knowledge of English lets them perform many activities that would not be possible if they had not known the language. They can watch films in English, communicate in English, be a student of English, they can read texts in English and have good job prospects in the future. Yet, they do not feel their identity has been influenced by the knowledge of English. Such reasoning may have resulted from their idea of identity as the core, the essence of who they are, probably static and impervious to changes. This may be a kind of ego, a kind of "me" which makes a person unique regardless of languages they speak. But it is only a speculation.

Gender differences were found in the data. Females were more concerned about their personality and thus pointed to the openness, tolerance, and the increase of self-confidence as the effects of using a foreign language. Males, on the other hand, did not seem to care that much about these influences. Instead, they focused more on job prospects.

During the analysis it also appeared that perceptions of self are related to age, nationality, and student status. Undergraduate first year Polish students, 
young and enthusiastic, are more communicatively oriented, which suggests that social relations are important for them. This should not be surprising when the social context is taken into account. At the time of data collection they had been students for half a year and in the process of understanding what is involved in this position. They were constructing their student identity on the basis of their own beliefs and attitude to life, but they also relied on observations, conversations, and discussions with others.

Graduate students, older, more experienced and aware of their social positioning as students, realise that communication is important but they are also concerned about their future careers and self-confidence. In near future they will graduate from the university and enter the job market where skills and self-confidence are valued assets.

Erasmus + students are interested mostly in discovering and understanding other cultures. They usually keep the company of their compatriots and other Erasmus + students (cf. Sigalas, 2010) but they rely on their Polish contacts when such problems as an appointment with a doctor or administrative matters have to be handled.

Doctoral students - older than the other groups, most experienced, qualified and employed in various places - are more reflective. Few remember the communist days in Poland when there was a shortage of goods and a very limited access to sources of information other than the communist media. All acknowledge that English influenced them immensely-it allowed them to perceive life from different perspectives and let them find a place in the society.

Certain changes may be identified when the results of this study are compared with Piasecka's 2012 study. Both studies were carried out in the university context, both addressed identity issues of foreign language students but—which is self-evident - the participants were different. In both studies the participants highlight the importance of knowing a foreign language for relations with others (communication, getting to know others, being a student) and personality development (enhanced self-confidence, openness, tolerance of otherness, job opportunities). However, there are differences with respect to knowledge. In the current study the participants point to the knowledge of other cultures but do not imply that the knowledge of a foreign language allows them to better understand their own culture and language. Neither do they write about access to information but they point out to sources of entertainment. Such a change may be due to the omnipresence of the Internet along with easy access to it through mobile devices, for example. The participants might have become so used to this manner of obtaining information that they perceive it as something natural and self-evident.

Definitely, the context in which this study was conducted differs from the studies on immigrant adult identities in that the participants do not experience social unequality, marginalization or loss of social position because of the 
insufficient knowledge of the language though they may experience these but for other reasons, which is beyond the scope of this paper. Erasmus + and other foreign students seem to enjoy studying abroad. They stay abroad for a semester or two, and then they return to their home universities to complete their education. Although they may have problems concerning accommodation, health care or insufficient understanding of local traditions, they can always rely on the help and assistance of local students.

According to Norton (2013), identity is about how people understand their relationship to the world along with their possibilities for the future. Identity is also about constructing these relations. The participants of the study are aware of what is involved in being a foreign language student, what they can gain and what they can do in the future. As proficient foreign language users, they have a wide range of possibilities concerning their present activities and future employment. Through interactions with others by the medium of English they construct their identities of open-mindedness, tolerance, and understanding of other cultures.

\section{Conclusion}

Most research on identity and language learning takes place in adult immigrant contexts (e.g., Norton, 2013; Perdue, 1984; Rockhill, 1987a, 1987b) but some researchers are also concerned about study abroad contexts (e.g., Kingringer, 2004; Polanyi, 1995; Sigalas, 2010). Although foreign language learning has not been a hot issue in identity research, nevertheless, it also has effects on learners' perceptions of their identity. Foreign language learning usually takes place in formal educational settings in which foreign languages have the status of compulsory school subjects and the languages learned are not the means of communication of the society. Yet, they may be used to communicate with foreigners met in the streets or in the social media. Moreover, schools are the sites where the negotiation of identity occurs daily, especially in adolescence.

Any language a person speaks has some effects on their identity. Learning a new language at school is like accumulating cultural and symbolic capital that is necessary in developing one's understanding of the world and oneself. It is an investment into one's present and future (Norton, 2013). The participants of the study reported in this paper realise that the knowledge of English gives them power, prestige, and opportunities to live and work in a changing world of complex social relations. To understand others, they need to be open-minded and tolerant. The participants indicated that their open-mindedness and toler- 
ance increased as a consequence of learning English. Thus, their identity is dynamic and shaped by what they do.

As regards the participants who claim that their identity was not affected by learning a foreign language, the perception of their language identity is in contrast to the activities they perform through the medium of English. Possibly, for them identity is fixed, coherent, and stable, unaffected by what they do, that is, their performativity.

Postmodern identity is deeply rooted in a range of social practices of individuals. Since these practices vary, the individuals take different roles in these practices, they use language in various interactions, they occupy different positions in discourse. On the one hand, their language identities are dynamic and multilayered, on the other, they also include fixed, essential elements relating to cultural and biological characteristics (Bucholtz, 2003).

\section{References}

Bakhtin, M. (1981). The dialogic imagination: Four essays by M. M. Bakhtin. Austin: University of Texas Press.

Block, D. (2007a). Second language identities. London, New York: Continuum.

Block, D. (2007b). The rise of identity in SLA research, post Firth and Wagner (1997). The Modern Language Journal, 91, Focus Issue, 863-876.

Bourdieu, P. (1977). The economics of linguistic exchanges. Social Science Information, 16(6), 645-688.

Bourdieu, P. (1991). Language and symbolic power. J. Thompson (Ed.). (G. Raymond \& M. Adamson, Trans.). Cambridge, MA: Harvard University Press.

Bremer, K., Broeder, P., Roberts, C., Simonot, M., \& Vasseur, M.-T. (1993). Ways of achieving understanding. In C. Perdue (Ed.), Adult language acquisition: Cross-linguistic perspectives (vol. 2, pp. 153-195). Cambridge: Cambridge University Press.

Bremer, K., Roberts, C., Vasseur, M.-T., Simonot, M., \& Broeder, P. (1996). Achieving understanding: Discourse in interculrural encounters. London: Longman.

Bucholtz, M. (2003). Sociolinguistic nostalgia and authentification of identity. Journal of Sociolinguistics, 7(3), 398-416.

Butler, J. (1999). Gender trouble: Feminism and the subversion of identity. London: Routledge.

European Comission (2014). The Erasmus impact study. Effects of mobility on the skills and employability of students and the internationalisation of higher education institutions. Luxembourg: Publications Office of the European Union.

Firth, A., \& Wagner, J. (1997). On discourse, communication, and (some) fundamental concepts in SLA research. The Modern Language Journal, 81(3), 285-300.

Foucault, M. (1984). The order of discourse. In M. Shapiro (Ed.), Language and politics (pp. 108-138). New York: New York Press.

Gass, S. (1998). Apples and oranges: Or why apples are not oranges and don't need to be. A response to Firth and Wagner. The Modern Language Journal, 82(1), 83-90.

Goldstein, T. (1996). Two languages at work: Bilingual life on the production floor. New York: Mouton de Gruyter. 
Hall, J. K., Cheng, A., \& Carlson, M. (2006). Reconceptualizing multicompetence as a theory of language knowledge. Applied Linguistics, 27(2), 220-240

http://ec.europa.eu/programmes/erasmus-plus/opportunities/students en

Kanno, Y., \& Norton, B. (2003). Imagined communities and educational possibilities: Introduction. Journal of Language, Identity and Education, 2(4), 241-249

Kinginger, C. (2004). Alice doesn't live here anymore: Foreign language learning and identity reconstruction. In A. Pavlenko \& A. Blackledge (Eds.), Negotiation of identities in multilingual contexts (pp. 219-242). Clevedon, England: Multilingual Matters.

Kinginger, C. (2009). Language learning and study abroad. A critical reading of research. Basingstoke: Palgrave MacMillan.

Kramsch, C. (2013). Afterword. In B. Norton, Identity and language learning. Extending the conversation. 2nd ed. (pp. 192-201). Bristol, Buffalo, Toronto: Multilingual Matters.

Lantolf, J., \& Genung, P. (2003). "I'd rather switch than fight": An activity theoretic study of power, success, and failure in a foreign language classroom. In C. Kramsch (Ed.), Language acquisition and languae socialization (pp. 175-196). London: Continuum.

McMahill, C. (1997). Communities of resistance: A case study of two feminist English classes in Japan. TESOL Quarterly, 31(4), 612-622.

Menard-Warwick, J. (2005). Both a fiction and an existential fact: Theorizing identity in second language acquisition and literacy studies. Linguistics and Education, 16(3), 253-274.

Norton, B. (1997). Language, identity, and the ownership of English. TESOL Quarterly, 31, 409-429.

Norton, B. (2006). Identity: Second language. In K. Brown (Ed.), Encyclopedia of language and linguistics, vol. 5 (pp. 502-508). Amsterdam: Elsevier.

Norton, B. (2013). Identity and language learning. Extending the conversation. 2nd ed. Bristol, Buffalo, Toronto: Multilingual Matters.

Norton, B., \& Toohey, K. (2011). Identity, language learning and social change. Language Teaching, 44(4), 412-446.

Pavlenko, A., \& Blackledge, A. (2004). Introduction: New theoretical approaches to the study of negotiation of identities in multilingual contexts. In A. Pavlenko \& A. Blackledge (Eds.), Negotiation of identities in multilingual contexts (1-33). Clevedon, England: Multilingual Matters.

Perdue, C. (Ed.). (1984). Second language acquisition by adult immigrants. Rowley, MA: Newbury House.

Piasecka, L. (2012). Identity and language: A foreign language learning perspective. In E. Piechurska-Kuciel \& L. Piasecka (Eds.), Variability and stability in foreign and second language learning contexts (pp. 116-133). Newcastle upon Tyne: Cambridge Scholars Publishers.

Polanyi, L. (1995). Language learning and living abroad. In B. Freed (Ed.), Second language acquisition in a study abroad context (pp. 271-279). Amsterdam: Benjamins.

Puri, J. (2004). Encountering nationalism. Oxford: Blackwell.

Rampton, B. (1997). Displacing the 'native speaker': Expertise, affiliation, and inheritance. ELT Journal, 44, 97-101.

Reich, R. (1991). The work of nations. New York: Vintage.

Rockhill, K. (1987a). Literacy as a threat/desire: Longing to be SOMEBODY. In J. Gaskill \& A. McLaren (Eds.), Women and education: A Canadian perspective (pp. 315-331). Calgary, Alberta: Detselig Enterprises Ltd.

Rockhill, K. (1987b). Gender, language and the politics of literacy. British Journal of Sociology of Education, 18(2), 153-167. 
Sigalas, E. (2010). Cross-border mobility and European identity: The effectiveness of intergroup contact during the Erasmus year abroad. European Union Politics, 11(2), 241-265.

Weedon, C. (1997). Feminist practice and poststructuralist theory. 2nd ed. Oxford: Blackwell. 